\title{
A Vertical-Axis Off-Grid Squirrel-Cage Induction Generator Wind Power System
}

\author{
Peifeng Xu ${ }^{1}$, Kai Shi ${ }^{1,2, *}$, Feifei Bu ${ }^{3}$, Dean Zhao ${ }^{1}$, Zhiming Fang ${ }^{1}$, Rongke Liu ${ }^{2}$ and Yi Zhu ${ }^{4}$ \\ 1 School of Electrical and Information Engineering, Jiangsu University, Zhenjiang 212013, China; \\ xupeifeng80@ujs.edu.cn (P.X.); zhaodean228@126.com (D.Z.); fzm7889@ujs.edu.cn (Z.F.) \\ 2 KTK Group, Changzhou 212102, China; liurk@ktk.com.cn \\ 3 College of Automation Engineering, Nanjing University of Aeronautics and Astronautics, Nanjing 211106, \\ China; bufeifei1984@163.com \\ 4 Jiangsu Province Special Equipment Safety Supervision Inspection Institute-Branch, Wuxi 214171, China; \\ yishuang1009@163.com \\ * Correspondence: shikai80614@163.com; Tel.: +86-138-1547-1415
}

Academic Editor: Frede Blaabjerg

Received: 16 August 2016; Accepted: 9 October 2016; Published: 14 October 2016

\begin{abstract}
In order to broaden the limited utilization range of wind power and improve the charging and discharging control performance of the storage battery in traditional small wind power generation systems, a wind power system based on a vertical-axis off-grid induction generator is proposed in this paper. The induction generator not only can run in a wide wind speed range but can also assist the vertical-axis wind turbine to realize self-starting at low wind speed. Combined with the maximum power point tracking method, the slip frequency control strategy is employed to regulate the pulse width modulation (PWM) converter to control the output power of the proposed system when the wind speed and load change. The charge and discharge of the storage battery is realized by the segmented current-limiting control strategy by means of an electric power unloader device connected to the DC bus. All these implement a balanced and stable operation of the proposed power generation system. The experimental research on the $5.5 \mathrm{~kW}$ prototype system is developed, and the corresponding results verify the correctness and feasibility of the system design and control strategy. Some comparison experiments with a magnetic suspension permanent magnet synchronous generator (PMSG) demonstrate the application prospect of the proposed vertical-axis off-grid induction generator wind power system.
\end{abstract}

Keywords: induction generator; wind power generation system; vertical axis; off grid; slip frequency control; segmented current-limiting control

\section{Introduction}

As a clean renewable energy source, wind power has seen a rapid development in the 21st century, thanks to its several inherent advantages including its vast quantity, wide regional distribution and zero pollution. Although wind is unstable, it can be predicted online. Although high power grid-connected wind turbines are not suitable for application in climate-sensitive places, wind power generation can be applied to supply electric power directly, and sometimes in an auxiliary way if the wind is intense. When the wind is weakened, the power grid or the battery meets the demands for electricity. With this consideration, the wind power generation, complemented with other power supplies, is an effective electric power reservation for industry and daily life.

The propeller-type horizontal axis wind turbine is the mainstream of large-scale commercial wind power generations, since it meets industrial requirements and its efficiency is much higher than traditional vertical axis wind turbines (VAWTs). However, VAWTs have some additional advantages, 
such as simple structure without a yawing device to align toward the wind direction, convenient maintenance since the gear box and the generator are installed on the ground, low material and manufacturing requirements, low starting torque and running noise [1], and suitability for low wind speed operation.

The reported Savonius wind turbine belongs to drag-type VAWT [2], and the wind energy utilization coefficient is much less than horizontal axis wind turbines and the late proposed Darrieus lift-type VAWT [3,4]. Although many improvements were developed to increase the utilization coefficient of the Savonius wind turbine, such as blade number, blade overlap ratio, eccentricity coefficient, and wind turbine structure [5,6], the results are not satisfied. Therefore, in the past two decades, many companies have been devoted to overcoming their deficiencies and developing the Darrieus and other modified VAWT products: the improved lift-type Darrieus VAWT of Cleanfield Energy from Canada, the Windside series VAWTs of Windside from Finland, the MW1100 VAWT of Magwind, the Delta series VAWTs of PacWind, the Windspire VAWTs from the USA, and the StatoEolien VAWT of Gual industrie from France, and many other VAWT products have been devoted to market use. Recently, the main pursuit of goals and trend of the development includes low start-up wind speed, high wind energy utilization coefficient, low noise operation and beautiful appearance. Thus, a more efficient wind turbine, more advanced bearing technology such as a magnetic suspension bearing, design and control technology of the wind power generator, and wind energy conversion system have become popular research hot of VAWTs. In this paper, research work mainly relates to the control of the wind power generator and energy management system.

Squirrel-cage induction generators (SCIGs) and permanent magnet synchronous generators (PMSGs) are both popular in small and medium wind power systems. The PMSG with the direct drive structure has a higher efficiency under low wind speed. Since an additional excitation controller is not necessary, the control of the PMSG is very simple. Therefore, current mainstream VAWT products all chose the PMSG as the wind power generator. However, the significantly increasing price of rare-earth permanent magnets over the last several years has resulted in a high cost of PMSG. Besides this, the control system is inflexible without regulating the excitation. The traditional structure of the uncontrolled rectifier plus DC-DC converter employed in PMSG systems resulted in only one controllable component being used when the maximum power point tracking, the energy storage controlling of the battery, and required load power following are realized simultaneously. For these reasons, it is difficult for the whole PMSG wind power system to achieve the best working state. Moreover, the performance of the batteries will be affected due to its inability to form a unified energy management system. Furthermore, a self-starting auxiliary device is necessary for the inherent cogging torque of the PMSG when it is employed in the VAWT $[7,8]$.

The SCIG has some remarkable advantages including simple structure, high robustness, easy maintenance, and the more obvious advantage of price over PMSGs due to the increasing cost of permanent magnets. The SCIG wind power system has been put on the wind power market by the wind turbine manufacturer in Denmark since the 1980s, and is still occupying a considerable market share now. The Bonus Company has always regarded SCIGs as the main products. For SCIGs, the required reactive power to complete voltage buildup is supplied by a self-excited capacitor $[9,10]$ or power electric converter [11,12]. The structure connecting in series with the power electronic converter is most suitable for the wind power system than other structures $[13,14]$. This scheme can regulate the active and reactive power at the same time through a flexible control strategy, and realize the bidirectional flow of energy. At the same time, this scheme can solve the coordination control problem of the generator unit and the storage battery, realize the multi-state operation of the system, and assist the VAWT to complete self-starting. In addition, the favorable capability of the SCIG to operate in flux-weakening regions broadens the operational speed ranges of this generator. No matter how the output voltage frequency and wind speed change, the pulse width modulation (PWM) converter can help to output stable DC voltage over wide wind speed ranges. With this consideration, the research on SCIG in vertical-axis wind turbines is developed in this paper. 
At present, researches on vertical-axis SCIG wind power systems are mainly focused on gridconnected wind turbines [15]. Compared with the grid-connected systems, the off-grid system is much more flexible and diversified [16,17]. For an off-grid vertical-axis system, it has some additional advantages including convenient installation and improved power generation efficiency. Therefore, the off-grid vertical-axis SCIG wind power system is very suitable for directly supplying production electricity without power network, or an auxiliary electricity power supply.

In order to solve the problems of the limited utilization range of wind power and the inability to achieve the best performance of the storage battery in traditional off-grid wind turbines, the vertical-axis off-grid SCIG wind power system is proposed in this paper. Comprehensive studies focusing on the control strategy of SCIG, the charge and discharge control of the storage battery, the system energy management strategies and on-load running control are carried out. Then, experimental researches on a $5.5 \mathrm{~kW}$ prototype system were developed to verify the correctness and feasibility of the system design and control strategy. Finally, some practical operation comparison tests with the same power level magnetic suspension PMSG wind turbine under the same wind environment are carried out, and whose results demonstrate the application prospect of the proposed vertical-axis off-grid SCIG wind power system.

\section{System Structure and Working Principle}

The block diagram of the proposed vertical-axis off-grid SCIG wind power system is shown in Figure 1, where the vertical-axis off-grid induction generator wind power system is mainly composed of a squirrel-cage induction wind generator, a wind power generation system controller, a three-phase full-bridge converter and storage battery. The single-phase or three-phase inverter, the corresponding DC load, and the electric power unloader device are connected to the storage battery in parallel.

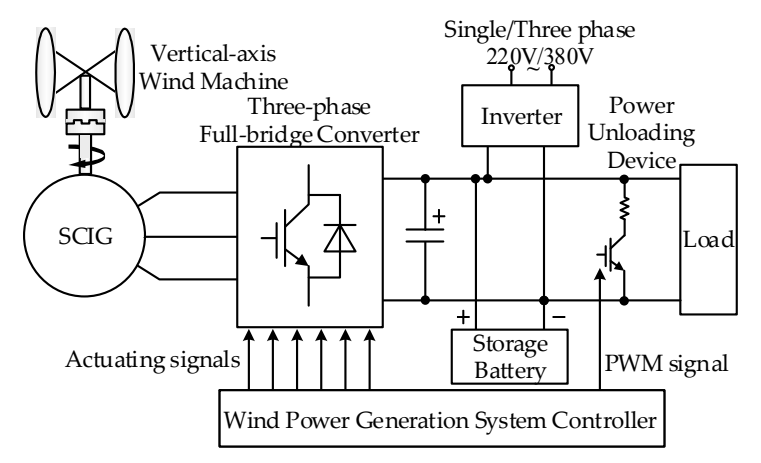

Figure 1. Block diagram of the vertical-axis off-grid squirrel-cage induction generator (SCIG) wind power system.

When the wind speed reaches the start-up speed, the wind machine is launched by the SCIG to realize self-starting, where the SCIG is driven by a storage battery. At this moment, the full-bridge converter is working in the state of an inverter, and the SCIG is running in the state of a motor. When the rotating speed of the SCIG exceeds the set speed of voltage buildup, the SCIG begins to enter the state of a generator. After this procedure, the active power is transferred from the SCIG to the outside load or inverter through the converter. At the same time, the SCIG needs to absorb the corresponding reactive power. Therefore, the whole wind power system can realize the bi-directional electric energy flow.

The storage battery is directly connected in parallel to the output bus, and the characteristic of the battery brings a clamping effect on the DC bus voltage. The electric power unloader device connected across the bus bar is composed of power resistance and power switch. The system controller sends the PWM drive signal to the power switch to adjust the resistance power continuously, and to absorb the excessive electric energy in the system, which makes the wind turbine operate in the optimum power state. 
When the output power of the SCIG is greater than the load power, the storage battery is charged by the system. If the charging current is too large, the power switch in the electric power unloader device circuit will turn on. Thus, the DC bus voltage keeps rising slowly with the storage battery being charged, until the DC bus voltage reaches the float charge voltage. After that, the duty ratio of the power switch in the electric power unloader device circuit is adjusted to keep the float charge current of the storage battery very small, and the DC bus voltage will be maintained to be constant. When the output power of SCIG is less than the required load power, the electric power unloader device is disconnected from the DC bus, and the storage battery begins to discharge if it has enough energy to transfer to the DC bus. The storage battery is not removed automatically until the bus voltage of the storage battery drops to the discharge cut-off voltage. It means that the capacity of the storage battery has reduced to a limited value. The alarm signal with the function of promptly removing the load will be sent to the system controller.

From the above discussion, it can be seen that the operation state of the system depends on the relationship between the output power of the SCIG and the load power. It is very important to control the optimal output power of SCIG flexibly and effectively. Secondly, in the process of charging the storage battery, the electric power unloader device has an auxiliary guiding function to the power flow direction. By monitoring the state of the battery in real time, the duty cycle of the PWM signal of the unloader device is adjusted to absorb the power which exceeds the capacity of the storage battery in the electric power unloader device. In other words, the main function of the energy management system is to control the generator unit and the storage battery to operate under the best condition.

\section{System Control Strategy}

\subsection{Wind Power Generator Control}

\subsubsection{Assisted Self-Starting Control Strategy}

When the wind speed reaches the start-up speed, the three-phase full-bridge converter makes the DC output voltage of the storage battery change to a variable-voltage variable-frequency AC voltage by a fixed sinusoidal PWM control strategy, which produces a circular rotating magnetic field with continuously increasing amplitude and frequency inside the generator. Accordingly, the motor operation of the SCIG is completed, and the rotating rotor helps to realize the self-starting of the wind machine. When the wind turbine is driven to reach the set speed, the system enters the state of voltage buildup. At this point, if the wind speed is too low, the output power of the wind machine will also be a small value. Consequently, the voltage building up is automatically stopped and the system must wait for the next large wind speed. If the output power is large, then the system will enter from normal a state into a power generation state. In this state, the closed-loop control of the output power is achieved. The schematic diagram of an assisted self-starting control strategy is shown in Figure 2.

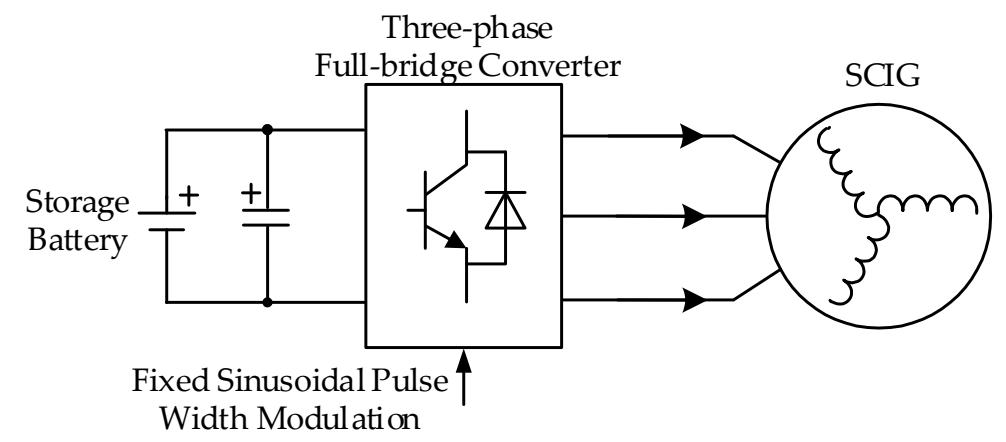

Figure 2. Schematic diagram of an assisted self-starting control strategy. 


\subsubsection{Power Generation Operation Control Strategy}

The control strategies adopted in the induction motor power generation system mainly include rotor flux linkage orientation [18], stator flux linkage orientation [19], direct torque control [20] and slip frequency control [21]. Among them, the slip frequency control has achieved very good dynamic and static performance in a dual stator-winding induction power generating system operating in a constant power area [22,23]. Without flux linkage observation, torque estimation and complex coordinate transformation, this method has a better real-time performance for saving the current loop affecting the system dynamic performance. The generator of the off-grid induction wind power generation system often runs in the constant torque region, and enters into the constant power area only after it reached the rated output power. Therefore, it is a new attempt for us to employ slip frequency control in the vertical-axis off-grid induction generator wind power system proposed in this paper. The detailed principle and implementation of this slip frequency control strategy is described below.

For simplicity, the power loss in the electromechanical conversion process is neglected, and it is also assumed that the output electromagnetic power $P_{\text {out }}$ generated by the SCIG is equal to the input mechanical power $T_{\mathrm{e}} \omega_{\mathrm{r}}$. Hence, the relationship $P_{\text {out }}=T_{\mathrm{e}} \omega_{\mathrm{r}}$ holds. However, in the wind power system, the change of the rotational speed has a very big inertia link. Thus the rotational speed can be regarded to be constant during the transient adjustment of electromagnetic parameters of the generator. Thus the following expression can be obtained as Equation (1):

$$
\frac{\mathrm{d} T_{\mathrm{e}}}{\mathrm{d} t}=\frac{1}{\omega_{\mathrm{r}}} \frac{\mathrm{d} P_{\text {out }}}{\mathrm{d} t}
$$

The output power of the SCIG changes with the fluctuation of the wind speed. By adjusting the electromagnetic torque of the generator rapidly, the output power can be controlled to track the maximum output power point, and thus to achieve the maximum wind energy tracking. Moreover, the electromagnetic torque of the induction motor $T_{\mathrm{e}}$ is closely related to the slip frequency, which can be approximately expressed as Equation (2):

$$
T_{\mathrm{e}} \approx 3 n_{p}\left(\frac{U_{s}}{\omega_{1}}\right)^{2} \frac{s \omega_{1}}{R_{r}{ }^{\prime}}
$$

where $n_{p}$ is the number of pole-pairs, $U_{s}$ and $\omega_{1}$ are phase voltage and angular frequency of the stator, $s$ is the slip ratio, and $R_{r}{ }^{\prime}$ is the rotor phase resistance converted to the stator side.

By neglecting the leakage impedance voltage drop of stator winding, the stator phase voltage is Equation (3):

$$
U_{s} \approx E_{g}=\frac{1}{\sqrt{2}} \omega_{1} N_{s} k_{N_{s}} \Phi_{\mathrm{m}}=\frac{2 \pi}{\sqrt{2}} f_{1} N_{s} k_{N_{s}} \Phi_{\mathrm{m}} \approx 4.44 f_{1} N_{s} k_{N_{s}} \Phi_{\mathrm{m}}
$$

where $f_{1}$ is the frequency of stator flux, $N_{s}$ is the number of turns per phase stator winding, $k_{N_{s}}$ is the winding coefficient of stator fundamental harmonic, and $\Phi_{\mathrm{m}}$ is the air-gap flux per pole.

Substituting Equation (3) into Equation (2), the following electromagnetic torque equations can be obtained:

$$
\begin{aligned}
T_{\mathrm{e}} & \approx K_{m} \Phi_{\mathrm{m}}^{2} \frac{\omega_{\mathrm{s}}}{R_{r}{ }^{\prime}} \\
K_{m} & =\frac{3}{2} n_{P} N_{s}{ }^{2} k_{N_{s}}^{2}
\end{aligned}
$$

where $\omega_{\mathrm{s}}$ is the slip frequency. According to Equation (4), it can be seen that the electromagnetic torque $T_{\mathrm{e}}$ is proportional to the slip frequency $\omega_{\mathrm{s}}$. The prerequisite is that the amplitude of the air-gap flux should remain constant, and the slip frequency $\omega_{\mathrm{s}}$ cannot exceed the maximum value $\omega_{\text {smax }}$. It means that the generator is working under a steady condition all the time. Therefore, the regulation of $\omega_{\mathrm{s}}$ can achieve the purpose of controlling the electromagnetic torque of the generator, and then adjust the output power of the generator with the changes or fluctuations of wind speed and load, and ultimately achieve the maximum power tracking. 
The detailed block diagram of the slip frequency control strategy for the SCIG is shown in Figure 3. The output voltage frequency of the three-phase converter is decided by the difference between the generator rotor angular velocity and the slip frequency obtained by the closed-loop regulator of the generator output power. The given value of the regulator is determined by the maximum power tracking control algorithm, and the feedback value is the detected by the actual output power. At the same time, the amplitude of the output voltage for the converter should be adjusted to keep the air-gap flux constant according to the real time rotor angular velocity of the generator. Finally, the effective control of the electromagnetic torque is realized, and the maximum power of the system is generated when the wind speed changes.

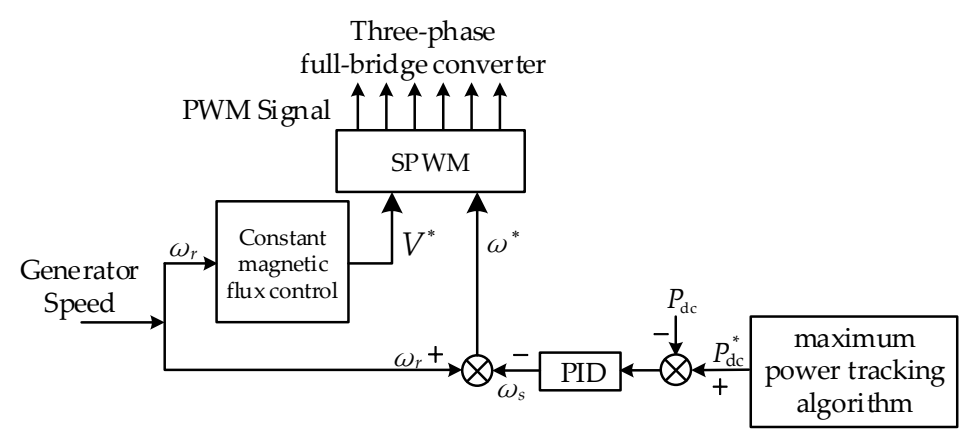

Figure 3. Block diagram of the slip frequency control strategy for the SCIG.

\subsection{Maximum Power Tracking Control}

As shown in Figure 3, the generator output power is controlled directly in the proposed wind power system. Therefore, the most suitable maximum power tracking control strategy should be the power control method [24]. The process of tracking the maximum power by using the power control method is displayed in Figure 4, where the three wind speed values satisfy the following relations $v_{1}<v_{2}<v_{3}$ and the bold polyline is the optimal power curve. It is assumed that the current wind speed is $v_{1}$, and the wind turbine is running at point $\mathrm{A}$ (the maximum power point under the wind speed $v_{1}$ ) with the corresponding speed $n_{1}$. If the wind speed rises to $v_{2}$ at this time, the output mechanical power of the wind machine suddenly increases. However, the generator rotor speed will not change abruptly due to mechanical inertia. Accordingly, the working state of the SCIG is changed from point $A$ to point $E$. After this procedure, the generator output power is moving along the curve E-B because the electromagnetic torque of the generator is controlled in real time, and finally the new equilibrium is achieved at the point $B$. In other words, the output mechanical power of the wind machine is equal to the output power of the generator, and the final speed is stable at $n_{2}$. At this moment, the captured wind energy is the maximum energy converted by the wind turbine under the current wind speed. The generator operation status change process under other wind speeds can be analyzed by the similar process.

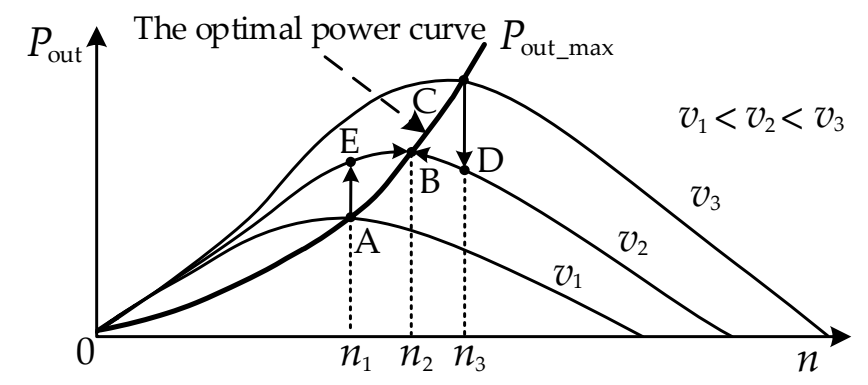

Figure 4. The schematic diagram of maximum power point tracking realized by the power control method. 
If the total loss, including mechanical loss, motor loss and so on, is neglected, the output power of the wind machine is proportional to the cube of the speed. Consequently, the maximum output power of generator can be obtained:

$$
P_{\text {out_max }}=k n^{3} P_{\mathrm{O}}
$$

where $k$ is the ratio coefficient related to the structure and the performance of the wind machine. According to Equation (6), the given optimal power $P_{\mathrm{dc}}{ }^{*}$ can be calculated by the current rotor speed. The error between the calculated value and the measured output power is sent to the regulator, and the output parameter is the slip frequency. Hence, the reference of the slip frequency is solved through continuous calculation in the PID regulator. The electromagnetic torque of the generator is changed by the slip frequency control to achieve the purpose of controlling the generator output power. When the wind speed rises from point $\mathrm{A}$ to point $\mathrm{B}$, the given power optimal $P_{\mathrm{dc}}{ }^{*}$ is also increased. The error input of the PID regulator is increased, and thus the slip becomes larger. Through adjusting the frequency of the output voltage of the PWM converter, the generator output power is regulated. After several times of adjustment cycle, the generator can be running stably at point $\mathrm{E}$.

\subsection{Storage Battery Control Strategy}

\subsubsection{System Energy Management Strategy}

The charging and discharging control of the storage battery plays an important role in the whole energy management system. In the off-grid wind power system, the change of wind speed and load affects the power flow direction, which decides the working state of the battery. The schematic diagram of power flowing direction under different working states of the battery is shown in Figure 5. Therefore, the charging and discharging control of the storage battery in the system cannot employ the traditional control strategy of the lead-acid battery, since the influence of wind speed and load change should be considered simultaneously.

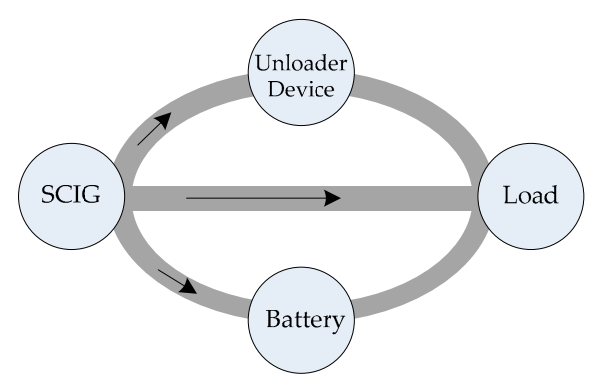

(a)

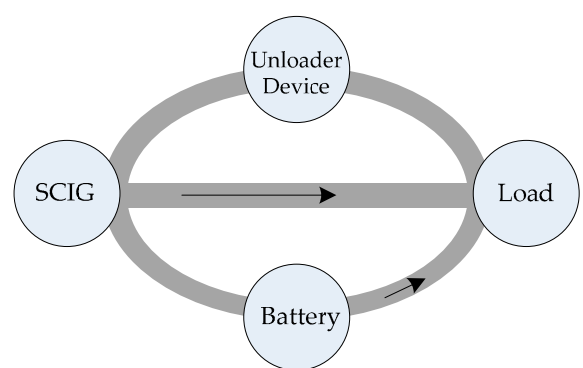

(b)

Figure 5. The schematic diagram of power flowing direction under different working states of the battery: (a) under the charging working state; and (b) under the discharging working state.

\subsubsection{Charging and Discharging Control Strategy}

In order to avoid the current spike caused by the bus voltage fluctuation under the big change of wind speed and load, and to simultaneously limit the charging and discharging current of the battery, the combination control scheme of phased charging and limited current charging is proposed for charging and discharging the control of the battery in this paper [25]. According to the bus voltage, the charging and discharging of the battery can be divided into four stages. In each stage, the limited current charging scheme is employed:

(1) Stage I: bus voltage < discharge cut-off voltage

In this stage, the battery is not allowed to discharge. Thus in this stage, the lower limit of the current is zero, and the upper limit is the maximum charge current value. After a charge process with 
a maximum charge current which makes the charge speed as quick as possible, the system will enter into Stage II.

(2) Stage II: discharge cut-off voltage $<$ bus voltage $<$ nominal voltage

The battery can operate in the charging or discharging state while the battery is not fully charged in this stage. The lower and upper limits of the current are both the allowed maximum charge current and discharge current for the system. This stage is a stable state, and may enter Stage III once charged.

(3) Stage III: nominal voltage $<$ bus voltage $<$ floating charge voltage

The battery can also operate in the charging or discharging state in this stage, and the battery is slightly fully charged. The upper and lower limits of the current are the allowed maximum charge current and discharge current respectively. The Stage III is a stable state, and it can enter into Stage IV once charged, or into State II once discharged.

(4) Stage IV: floating charge voltage $<$ bus voltage $<$ average charge voltage

The battery is fully charged in this stage, and can operate in the charging or discharging state. However, it is not permitted that the battery is charged by a large current for a long time. In this case, the lower limit of the current is the maximum discharge current value, and the upper limit of that is the floating charge current. This stage will enter into Stage III once discharged.

According to the DC bus voltage of the system, the working state of the whole system is divided into the above four stages. However, the variations of the charge and discharge current have a great influence on the battery capacity and life. Therefore, the limits of the charge and discharge current are also given in four stages.

\subsubsection{Actual Current Control}

In order to achieve the limitation of charging current limit, a closed loop regulation, by adjusting the duty ratio of the power switch in the electric power unloader device, is employed. The power consumption of the unloader device is proportional to the duty ratio:

$$
P_{R} \approx \frac{1}{T} \int_{t_{0}}^{t_{0}+D T} U_{\mathrm{dc}}^{2} / R \mathrm{~d} t=D U_{\mathrm{dc}}^{2} / R
$$

where $T$ is the switching cycle of the power switch, $D$ is the duty ratio, and $R$ is the value of power resistance.

The structure diagram of the close-loop control strategy for the charge current is shown in Figure 6. In Figure 6, the given charge current is chosen by the above divided stages according to the DC bus voltage of the system. The difference between the measured current and the given value is used to get the increment of the duty cycle $\mathrm{D}$. The duty ratio in the current switch cycle is obtained by adding this increment and the last duty ratio. In order to improve the dynamic response performance under the sudden change of the load, the load power feed-forward control is introduced into the control. It can prevent the battery from charging current spikes in the process of a sudden unload, and reduce the extra burden of the battery during a sudden load.

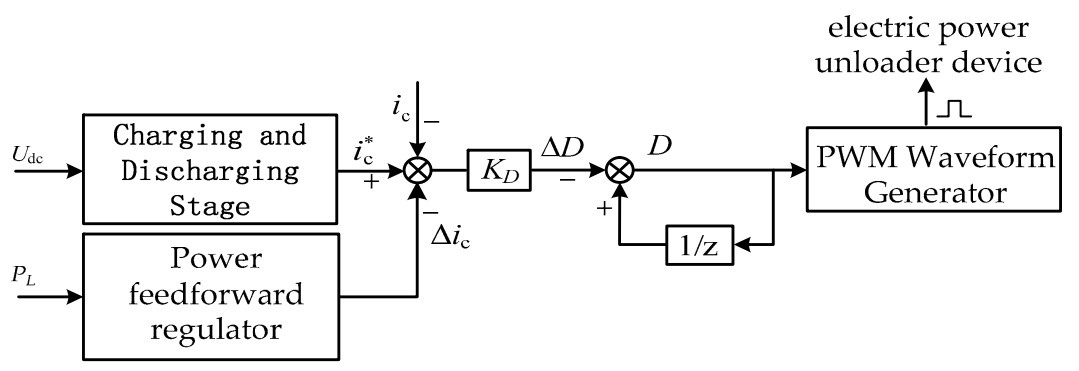

Figure 6. The structure diagram of the charge current close-loop control strategy. 
The protection of the storage battery in the discharging process is mainly to avoid its over discharge. The maximum discharge current and the lowest discharge voltage are both set to realize this protection. If the battery is over discharging within a certain period of time, an alarm signal is sent out to remove the load. Otherwise, the system will give a mandatory instruction to remove the load forcibly if no response is available.

\section{Experimental Verification and Comparative Experiments}

\subsection{Experimental Verification}

The experimental verification is carried out on the wind power generation simulation platform in the laboratory. The platform is mainly composed of an induction motor prime mover, a frequency converter, an SCIG wind power generator, storage batteries and a digital control system. The induction motor is controlled by a frequency converter to simulate and achieve the characteristic of the wind turbine. The other specific experimental parameters are shown in Table 1. The control system is composed of a Digital Signal Controller (MC56F8037, NXP Semiconductors, Eindhoven, The Netherlands) and a Complex Programmable Logic Device (M4A5-64, Lattice Semiconductor, Portland, OR, USA). By detecting the various parameters, including the DC bus voltage, current and power, the operating state of the SCIG and storage battery are evaluated. The system gives the switch driving signals of the three-phase full-bridge converter and electric power unloader device by the system controller, and finally realizes the maximum power point tracking and stable operation.

Table 1. Relevant experiment parameters of the off-grid SCIG wind power system.

\begin{tabular}{cccc}
\hline \multicolumn{2}{c}{ Generator Parameters } & \multicolumn{2}{c}{ Other Parameters } \\
\hline Rated power & $5.5 \mathrm{~kW}$ & Storage Batteries & $16 \times 12 \mathrm{~V} / 20 \mathrm{Ah}$ \\
Rated speed & $1450 \mathrm{rpm}$ & Power resistance & $6.4 \Omega / 7.5 \mathrm{~kW}$ \\
Rated line voltage & $154 \mathrm{~V}$ & Wind turbine & $200 \mathrm{rpm} / 5 \mathrm{~kW}$ \\
Pole pairs & 2 & Drive ratio & $1: 7.25$ \\
\hline
\end{tabular}

In order to realize the self-starting at a much lower wind speed, the sinusoidal PWM strategy is applied to convert the DC voltage of the battery to the constant frequency AC voltage for the motor-operated running state. The experimental results under this state are neglected in this paper because the control of the induction motor has received much attention.

During the normal operation process of the system, the battery is always connected to the DC bus, so the bus voltage is kept in a stable value in the process of voltage buildup. When the wind speed reaches the cut-in speed, the generator starts to build up the voltage. With the help of the aided excitation provided by the storage battery, the internal flux of the generator increases with the increment of the voltage amplitude of the SCIG. The DC bus voltage is controlled by the close-loop regulator until the generator enters into the generation state. Experimental results with no-load under voltage buildup, and that shut down at $1450 \mathrm{rpm}$, are shown in Figure 7, where Figure 7a shows the waveform of voltage buildup at the rated speed of $1450 \mathrm{rpm}$ and Figure $7 \mathrm{~b}$ shows the experimental waveform of the corresponding shutdown process. In order to avoid the impact of the current spikes in windings and the vibration of the mechanical structure, the terminal voltage of the generator is decreased in the form of ramp function in the shutdown process. Therefore, the excitation energy inside the generator can be released slowly.

Experimental waveforms at variable wind speeds are illustrated in Figure 8. Figure 8a shows the waveforms of the bus voltage, the bus current, and the phase current when the generator speed increases from $700 \mathrm{rpm}$ to $1100 \mathrm{rpm}$ within $0.5 \mathrm{~s}$. When the rotor speed is $700 \mathrm{rpm}$, the output power of the bus bar is about $750 \mathrm{~W}$, and the charge current of the battery is $3.6 \mathrm{~A}$. With the rotor speed rising, the speed slip becomes bigger, and then the phase current increases correspondingly. As the DC bus power flows into the battery, the charge current of the battery increases and reaches the allowable 
maximum current value. After this procedure, the bus voltage rises rapidly, and the excessive energy is absorbed into the electric power unloader device through adjusting the duty ratio of the switches by the closed-loop control of the charge current. When the battery charging state tends to Stage IV, the bus voltage gradually falls and returns to the float charge voltage $210 \mathrm{~V}$, and the output power is $3 \mathrm{~kW}$. Figure $8 \mathrm{~b}$ shows the waveforms of the system current and voltage when the generator rotor speed decreases from $1100 \mathrm{rpm}$ to $700 \mathrm{rpm}$ in $0.5 \mathrm{~s}$. The high frequency shadow of bus current is caused by the chopping current flowing in the power load. Due to the output power of the system being proportional to the cube of the rotator speed, the maximum power tracking control can be realized under variable rotor speed.

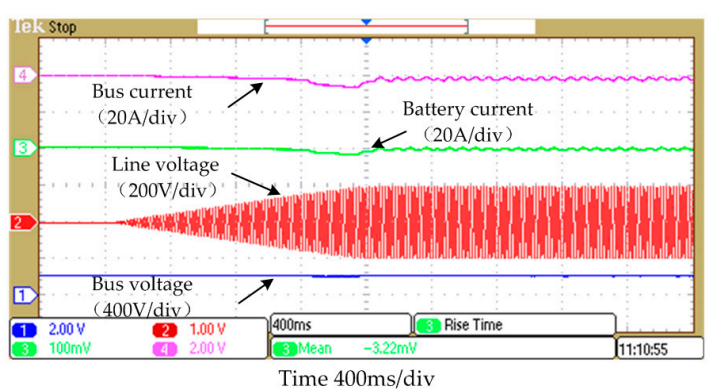

(a)

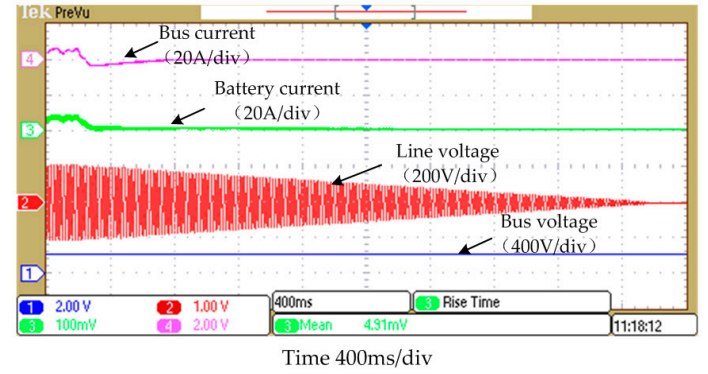

(b)

Figure 7. Experimental waveforms under voltage buildup and shutdown states at $1450 \mathrm{rpm}$ for the SCIG wind power system: (a) voltage buildup; and (b) shutdown.

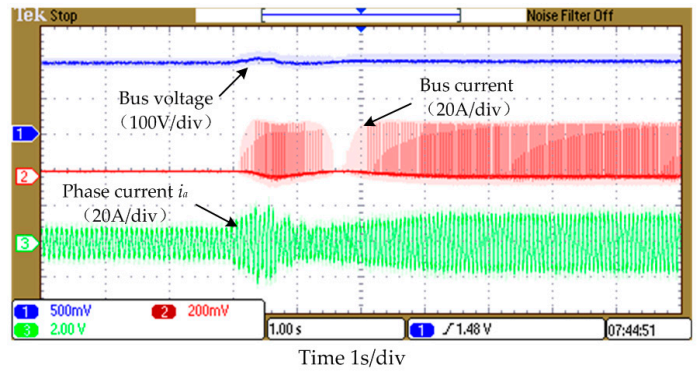

(a)

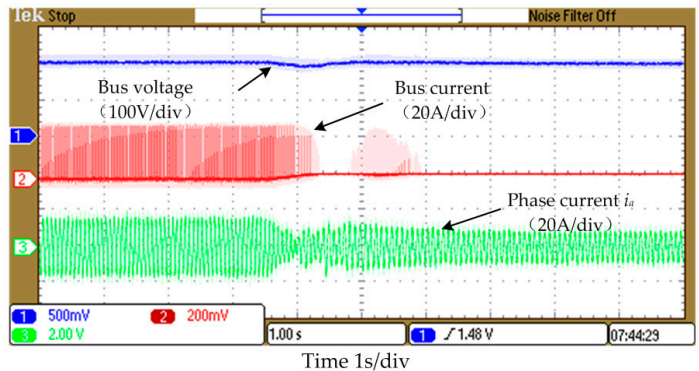

(b)

Figure 8. Voltage and current waveforms under variable speed operation for the SCIG wind power system: (a) from $700 \mathrm{rpm}$ to $1100 \mathrm{rpm}$; and (b) from $1100 \mathrm{rpm}$ to $700 \mathrm{rpm}$.

Experimental waveforms of the system with step load changes are exhibited in Figure 9. In Figure 9a, the initial generator speed is $1450 \mathrm{rpm}$, and the stable output power of the system is about $4.5 \mathrm{~kW}$. At this moment, the battery is charged at the maximum charge current of $4 \mathrm{~A}$, and the electric power unloader device works orderly to absorb the excessive power. After the system removes a load power of $3.5 \mathrm{~kW}$ suddenly, the battery current has an upward trend, and the duty ratio of the power switches in the electric power unloader device increases to absorb the surplus power. Until the battery current falls back to the normal range of charging, the transient time is about $400 \mathrm{~ms}$. The output current is the sum of the load current and the discharge current, which is equal to the difference between the bus current and the battery current. Figure $9 \mathrm{~b}$ gives the system waveforms with a sudden load power of $3.5 \mathrm{~kW}$. The generator runs at a low speed of $880 \mathrm{rpm}$, and the output power is $1 \mathrm{~kW}$. At this point, the battery is charging at the maximum charge current of $4 \mathrm{~A}$, and the electric power unloader device works orderly to absorb the excessive power. When the load $3.5 \mathrm{~kW}$ suddenly increases, the output power of the generator is not great enough to provide the load power. Therefore, the battery must output electric power to balance the load power. The battery discharges at the current of $12 \mathrm{~A}$, and the PWM switch signal of the power switches, in the electric power unloader device, is off. 
The experimental results show that the process of voltage buildup and shutdown is reliable and stable. The charge and discharge current of the battery can be controlled effectively under the condition of variable speed operation and stepping change of the load. Following the load power effectively, the generator can achieve maximum power tracking by the slip frequency control, and the system has a quick response.

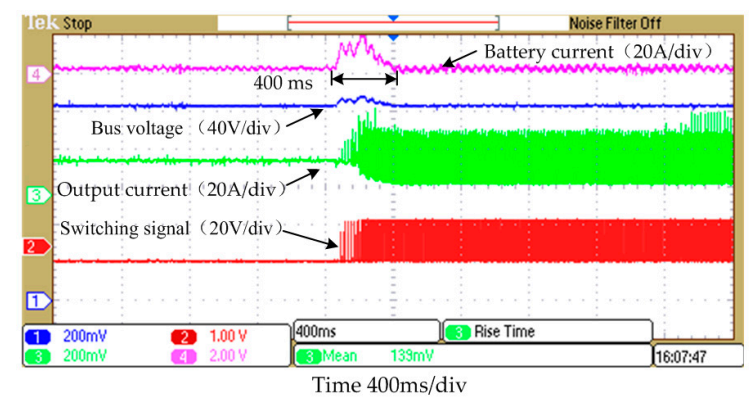

(a)

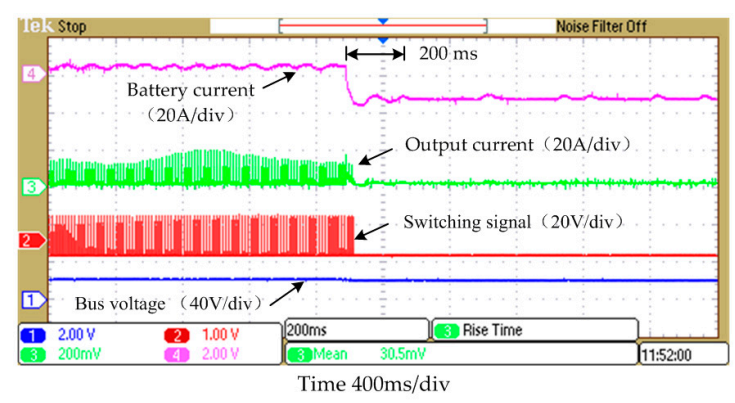

(b)

Figure 9. Voltage and current waveforms under the step, load and unload for the SCIG wind power system: (a) sudden unload of $3.5 \mathrm{~kW}$; and (b) step load of $3.5 \mathrm{~kW}$.

\subsection{Comparative Experiments}

In order to verify the power performance of the proposed vertical-axis off-grid SCIG wind power system, comparative experiments are developed to investigate the power generation capacity of the wind turbine. Here, the designed vertical-axis off-grid SCIG wind power system is compared with the PMSG wind turbine system with a magnetic suspension bearing which is generally regarded as an efficient small wind turbine. Two wind turbines employ the same wind machine and work in the same testing environment. The test platform in the wind field is shown in Figure 10. The parameters of the similarities and differences between the two wind power systems are shown in Table 2.

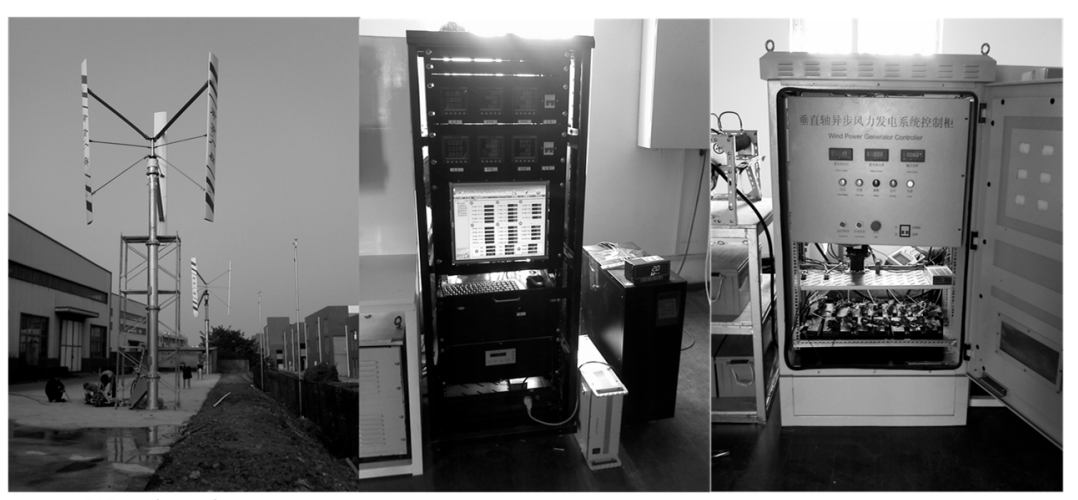

Wind turbines
System monitor
Control cabinet

Figure 10. Comparative experiments' test platform in the wind field.

Table 2. Parameters of the similarities and differences between the two wind power systems.

\begin{tabular}{ccc}
\hline Comparative Objects & SCIG Wind Power System & PMSG Wind Power System \\
\hline Wind machine & Same & Same \\
Rated power & Same & Same \\
Connection type & Speed increasing gear (1:7.25) & Magnetic suspension \& direct drive \\
Structure topology & Full-bridge converter & Uncontrolled rectifier + DC $/ \mathrm{DC}$ \\
System controller & One controller & Two controllers (starter + generation) \\
Storage battery & $16 \times 12 \mathrm{~V} / 20 \mathrm{Ah}$ & $9 \times 12 \mathrm{~V} / 100 \mathrm{Ah}$ \\
\hline
\end{tabular}


To reflect the real performance of the proposed wind power system, some factors such as site obstructions, terrain, and air density, are all taken into account before testing. In addition, the test data should be processed standardly. Specific data processing steps are as follows:

(1) The test data is recorded every second, and the maximum, minimum, mean and standard deviation of every ten minutes of data are calculated;

(2) Two wind turbines should be guaranteed to operate normally for more than $180 \mathrm{~h}$;

(3) All data is divided into many pieces per $0.5 \mathrm{~m} / \mathrm{s}$ wind speed, and the average for each piece of data is calculated;

(4) One-to-one correspondence of the average power and the average wind speed are finally achieved, from which the power curve is obtained.

According to the above analysis and process of test data, the power distribution of two different wind power systems under different wind speeds are achieved and shown in Figure 11. As shown in Figure 11, the power increases from $6 \mathrm{~m} / \mathrm{s}$ to $11 \mathrm{~m} / \mathrm{s}$ obviously, which is approximately in accordance with the maximum power curve of the wind machine. The applied magnetic suspension helps the PMSG system output more power at a very low wind speed. However, the average power of the designed SCIG system is slightly higher than the average power of the PMSG system at low wind speed. In addition, for the designed SCIG system, the higher power output is also achieved at high wind speed because of the more flexible control strategy. Although the magnetic suspension and direct drive structure are both employed in PMSG system to broaden the wind energy utilization range, the excellent control strategy and favorable system energy management can also help to prove the performance of SCIG systems. In comparison with the disadvantages of exorbitant price, complicated mechanical structure, additional starting controller and low reliability of the PMSG system, the merits of low cost, rugged construction, simple controller and flexible control strategy of the SCIG systems are more attractive for us. Although the employed uncontrolled rectifier and DC/DC converter limit the performance improvement of the PMSG system, the comparative experimental results are still convincing to us.

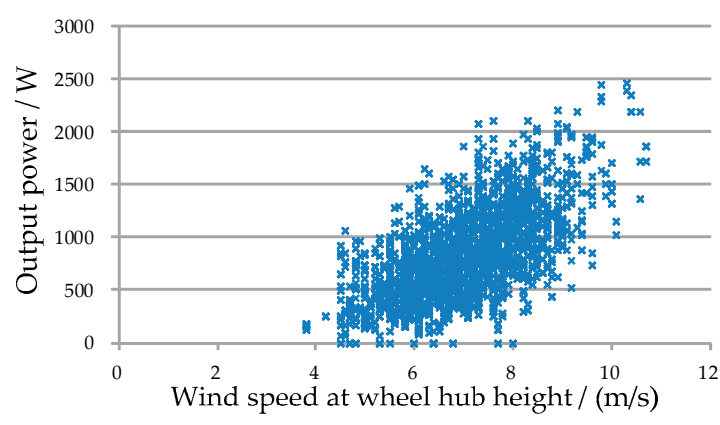

(a)

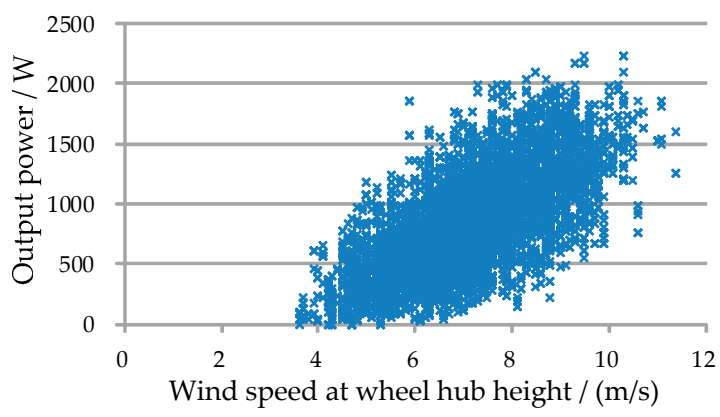

(b)

Figure 11. Power distribution under different wind speeds for two different wind power systems: (a) the SCIG wind power system; and (b) the PMSG wind power system.

\section{Conclusions}

By combining the novel H-type VAWT with the SCIG, this paper presented a novel vertical-axis off-grid induction generator wind power system with some remarkable advantages, including simple structure, high reliability and good economy compared with the traditional structure and magnetic suspension structure of the PMSG systems. In addition, the induction generator can operate in a wider rotor speed region and possess the useful self-starting function. Combined with the slip frequency control and maximum power point tracking control, the unified energy management system of the whole control system is realized through employing the three-phase full-bridge converter to achieve 
closed-loop control of the output power, and using the segmented current-limiting control strategy to implement the charging and discharging of the storage battery. The experimental results show that the proposed vertical-axis SCIG system can run reliably and stably with good performance. The experimental results of comparison with the PMSG wind power system in the same wind field further demonstrate the application prospect of the proposed SCIG system. When we develop the wind power industry with our own characteristics, it is of great significance to develop such a set of stable and reliable, economical and durable wind power systems, and to exploit better control performance for engineering application.

Acknowledgments: This work was supported in part by the National Natural Science Foundation of China under grant 51407085, the Postdoctoral Science Foundation of China under Award No. 2015M571685, the Fundamental Research Funds for the Central Universities under Grant NJ20160046, the grant from the Priority Academic Program Development of Jiangsu Higher Education Institution and Jiangsu University Senior Talents Special Project under award 13JDG111.

Author Contributions: All authors contributed to this work by collaboration. Peifeng Xu, Kai Shi, Feifei Bu, Dean Zhao, Zhiming Fang, Rongke Liu, and Yi Zhu are the main authors of this manuscript.

Conflicts of Interest: The authors declare no conflict of interest.

\section{References}

1. Mollerstrom, E.; Ottermo, F.; Hylander, J.; Bernhoff, H. Noise emission of a 200 kW VAWT. Energies 2016, 9, 19. [CrossRef]

2. Ushiyama, I.; Nagai, H.; Shinoda, J. Experimentally determining the optimum design configuration for Savonius rotors. Bull. JSME 1986, 29, 4130-4138. [CrossRef]

3. Kirke, B.K. Evaluation of Self-Starting Vertical Axis Wind Turbines for Stand-Alone Applications. Ph.D. Thesis, Griffith University, Brisbane, Australia, 1998.

4. Islam, M.; Ting, D.S.-K.; Fartaj, A. Aerodynamic models for Darrieus-type straight-bladed vertical axis wind turbines. Renew. Sustain. Energy Rev. 2008, 12, 1087-1109. [CrossRef]

5. Menet, J.L. A double-step Savonius rotor for local production of electricity: A design study. Renew. Energy 2004, 29, 1843-1862. [CrossRef]

6. Saha, U.K.; Thotla, S.; Maity, D. Optimum design configuration of Savonius rotor through wind tunnel experiments. J. Wind Eng. Ind. Aerodyn. 2008, 96, 1359-1375. [CrossRef]

7. Harrouz, A.; Benatiallah, A.; Harrouz, O. Direct Power Control of A PMSG Dedicated to Standalone Wind Energy Systems. In Proceedings of the 2013 IEEE 8th International Conference an Exhibition on Ecological Vehicles and Renewable Energies, Monte Carlo, Monaco, 27-30 March 2013.

8. Pawsey, N.C.K. Development and Evaluation of Passive Variable-Pitch VAWTs. Ph.D. Thesis, The University of New South Wales, Sydney, Australia, 2012.

9. Chan, T.F. Capacitance requirements of self-excited induction generators. IEEE Trans. Energy Convers. 1993, 8, 304-311. [CrossRef]

10. Bansal, R.C. Three-phase self-excited induction generators: An overview. IEEE Trans. Energy Convers. 2005, 20, 292-299. [CrossRef]

11. Liu, L.; Hu, Y.; Huang, W. Summary of technology of induction generator with power electronic converters. Trans. China Electrotech. Soc. 2005, 20, 1-7.

12. Ojo, O.; Davidson, I.E. PWM-VSI inverter-assisted stand-alone dual stator winding induction generator. IEEE Trans. Ind. Appl. 2000, 36, 1604-1611.

13. Simoes, M.G.; Bose, B.K.; Spiegel, R.J. Fuzzy logic based intelligent control of a variable speed cage machine wind generation system. IEEE Trans. Power Electron. 1997, 12, 87-95. [CrossRef]

14. Mclver, A.; Holmes, D.G.; Freere, P. Optimal Control of a Variable Speed Wind Turbine under Dynamic Wind Conditions. In Proceedings of the 1996 IEEE 31th International Conference on Industry Applications, San Diego, CA, USA, 6-10 October 2013; pp. 1692-1698.

15. Hu, W.; Wang, Y.; Song, X.; Wang, Z. Development of Vertical-Axis Wind Turbine with Asynchronous Generator Interconnected to the Electric Network. In Proceedings of the 2008 IEEE International Conference on Electrical Machines and Systems, Wuhan, China, 17-20 October 2008; pp. 2289-2293. 
16. Gu, W. Development and application of large-scale non-grid-connected wind power system. Autom. Electr. Power Syst. 2008, 32, 1-4.

17. Qi, Z.; Wang, S. Energy management under the coordination control framework for off-grid wind power generation system. ACTA Energ. Sol. Sin. 2009, 30, 503-508.

18. Alan, I.; Lipo, T.A. Control of a poly phase induction generator/induction motor power conversion system completely isolated from the utility. IEEE Trans. Ind. Appl. 1994, 30, 636-647. [CrossRef]

19. Seyoum, D.; Rahman, M.F.; Grantham, C. Terminal Voltage Control of a Wind Turbine Driven Isolated Induction Generator Using Stator Oriented Field Control. In Proceedings of the 2003 IEEE Applied Power Electronics Conference and Exposition, Miami Beach, FL, USA, 9-13 February 2003; pp. 846-852.

20. El-kafrawi, H.M.; Buamud, M.S. Torque Control of Squirrel-Cage Induction Generator Using Stator Oriented Field Control. In Proceedings of the 2015 IEEE 6th International Conference on Renewable Energy Congress (IREC), Sousse, Tunisia, 24-26 March 2015.

21. Huang, W.; Hu, Y. Research of the DTC control strategy for cage-type induction generator. Trans. China Electrotech. Soc. 2002, 17, 30-34.

22. Bu, F.; Huang, W.; Hu, Y.; Shi, K. An intergrated AC and hybrid generation system using dual stator-winding induction generator with static excitation controller. IEEE Trans. Energy Convers. 2012, 27, 810-812. [CrossRef]

23. Bu, F.; Huang, W.; Hu, Y.; Shi, J.; Shi, K. A stand-alone dual stator-winding induction generator variable frequency AC power system. IEEE Trans. Power Electron. 2012, 27, 10-13. [CrossRef]

24. Esmaili, R.; Xu, L.; Nichole, D.K. A New Control Method of Permanent Magnet Generator for Maximum Power Tracking in Wind Turbine Application. In Proceedings of the 2005 IEEE Power Engineering Society General Meeting, San Francisco, CA, USA, 16 June 2005; pp. 2090-2095.

25. Zhou, R.; Lu, J.; Wang, G.; Long, X.; Zhang, X.; Li, C. The Charging and Discharging Balance Control Strategy of Power Batteries for Hybrid Energy Storage. In Proceedings of the 2016 International Symposium on Power Electronics, Electrical Drives, Automation and Motion (SPEEDAM), Capri, Italy, 22-24 June 2016; pp. 265-269.

(C) 2016 by the authors; licensee MDPI, Basel, Switzerland. This article is an open access article distributed under the terms and conditions of the Creative Commons Attribution (CC-BY) license (http:/ / creativecommons.org/licenses/by/4.0/). 